\title{
STRATEGI PENINGKATAN DAYA SAING USAHA MIKRO TEMPE NASABAH LEMBAGA KEUANGAN MIKRO
}

\author{
Arasy Alimudin ${ }^{1)}$ Ramadhan Prasetya Wibawa ${ }^{2)}$ \\ Prodi Magister Manajemen Universitas Narotama ${ }^{1)}$ UNIVERSITAS PGRI MADIUN $^{2)}$ \\ arasybest@gmail.com ${ }^{1)}$ ramadhan@unipma.ac.id ${ }^{2)}$
}

\begin{abstract}
The problem faced by micro business tempe customer of micro financial institution (LKM) of Sidoarjo Regency so that can improve competitiveness of Micro Business of Tempe for business sustainability is loan interest rate and unstable of soybean price as main raw material of tempe product. The purpose of this study is to examine and determine alternative micro business tempe competitiveness strategy that has obtained financing from MFIs so as to create sustainability of business in the era of MEA competition amid widespread imports of soybeans. The method of research used mix method (mixed method) object of this research is micro entrepreneur of tempe product in village area sepande subdistrict of Sidoarjo district which is not member of cooperative and have become customer of Micro Finance Institution amount 10 person. The analysis method used in this research is SWOT Analysis, SWOT matrix then continued with QSPM (Quantitative Strategic Planning Matrix). The result of the research shows that the right competitiveness strategy is product development strategy by developing the type and variant of tempe product, especially the change of form and packaging which is more interesting and hygienic so that it can give the added value of the product and increase the selling price, which in turn will increase the business profit and can overcome the weaknesses in the burden of interest costs on loans provided by microfinance institutions.
\end{abstract}

Keywords: Strategy, Competitiveness, Micro Business, Product Development, SWOT, QSPM.

\begin{abstract}
Abstrak
Permasalahan yang dihadapi oleh usaha mikro tempe nasabah lembaga keuangan mikro(LKM) Kabupaten Sidoarjo sehingga dapat meningkatkan daya saing Usaha Mikro Tempe untuk keberlangsungan usaha adalah tingkat bunga kredit pinjaman dan tidak stabilnya harga kedelai sebagai bahan baku utama produk tempe.Tujuan dari penelitian ini dilakukan adalah untuk mengkaji dan menentukan alternatif strategi daya saing usaha mikro tempeyang telah mendapatkan pembiayaan dari LKM sehingga mampu menciptakan keberlangsungan usaha di era persaingan MEA ditengah maraknya impor kedelai.Metode penelitian yang digunakan mix methode ( metode campuran) obyek dari penelitian ini adalah pengusaha mikro produk tempe di wilayah desa sepande kecamatan candi kabupaten Sidoarjo yang bukan anggota koperasi dan telah menjadi nasabah Lembaga Keuangan Mikro berjumlah 10 orang. Metode analisis yang digunakan dalam penelitian ini adalah Analisis SWOT, matrik SWOT kemudian dilanjutkan dengan QSPM (Quantitative Strategic Planning Matrix).Hasil penelitian menunjukan strategi daya saing yang tepat adalah strategi pengembangan produk dengan melakukan pengembangan jenis dan varian produk tempe khususnya perubahan bentuk dan kemasan yang lebih menarik dan hiegenis sehingga dapat memberi nilai tambah produk dan meningkatkan harga jual, yang pada akhirnya akan meningkatkan keuntungan usaha dan dapat mengatasi kelemahan pada beban biaya bunga kredit yang diberikan oleh lembaga keuangan mikro.
\end{abstract}

Kata Kunci: Strategi, Daya Saing, Usaha Mikro, Pengembangan Produk, SWOT, QSPM. 


\section{PENDAHULUAN}

Berdasarkan data Badan Pusat Statistik (BPS), tahun 2012 jumlah penduduk miskin tercatat 27,76 juta orang atau sebesar 10,70 persen(Statistik, 2016).

Strategi percepatan penanggulangan kemiskinan seperti yang diatur dalam Peraturan Presiden Republik Indonesia No. 15 Tahun 2010 tentang percepatan penanggulangan kemiskinan dapat dilakukan dengan beberapa cara diantaranya adalah melalui peningkatan kemampuan dan pendapatan masyarakat miskin serta pengembangan dan jaminan keberlanjutan usaha mikro dan kecil. Berdasarkan data dari kementerian Koperasi dan UMKM tahun 2012-2014 kontribusi UMKM terhadap PDB nasional pada tahun 2013 adalah 57,6 persen (atas dasar harga konstan), dimana 30,3 persen berasal dari usaha mikro; 12,8 persen dari usaha kecil; dan 14,5 persen berasal dari usaha menengah dan kemampuan UMKM dalam penyerapan tenaga kerja sampai akhir tahun 2014 adalah 96,7 persen dari total tenaga kerja nasional dimana 87 persen dari tenaga kerja diserap oleh usaha mikro. Penyebaran sektor UMKM Indonesia sebagian besar masih bergerak dalam bidang usaha primer (pertanian, peternakan, kehutanan dan perikanan) yaitu sekitar 48,9 persen, bidang perdagangan sekitar 28,8 persen, industri pengolahan hanya 6,4 persen. Struktur usaha ini relatif berbeda dengan negara lain di ASEAN yang UMKMnya lebih dari 40 persen pada sektor jasa, bahkan untuk Malaysia jumlah UMKM yang berada pada sektor jasa mencapai 93,1 persen(Departemen Pengembangan UMKM. Bank Indonesia, 2016).

Pengembangan daya saing usaha mikro mutlak harus dilakukan untuk mengatasi kemiskinan di Indonesia, dan itu semua bermuara pada strategi peningkatan daya saing usaha mikro dan kecil.
Pertumbuhan daya saing UMKM sektor pengolahan di Indonesia dapat dilihat dari Indeks pertumbuhan nilai output UMKM di sektor industri pengolahan dimana sebagian besar provinsi mengalami penurunan antara tahun 2010 dan 2011. Dan Indeks pertumbuhan nilai output UMKM di sektor industri pengolahan di luar pulau Jawa pada tahun 2011 secara umum lebih baik dibandingkan dengan indeks pertumbuhan nilai output UMKM industri pengolahan di pulau Jawa. Perubahan indeks pertumbuhan nilai output UMKM dapat menjadi indikasi dampak dari perubahan pasar (kondisi permintaan, persaingan dengan produk impor, dll.) terhadap daya saing UMKM. Sedangkan khusus Provinsi Jawa Timur menunjukkan penurunan dari tahun 2010 memiliki indeks pertumbuhan output UMKM sebesar 45,18 menduduki peringkat 16 dan pada tahun 2011 menurun menjadi sebesar 14,14 menduduki perinkat 26 dari 32 provinsi di Indonesia (Departemen Pengembangan UMKM. Bank Indonesia, 2016).

Kemudahan akses pasar, baik domestik maupun internasional, akan sangat mendukung peningkatan daya saing UMKM Indonesia. Terkait dengan karakteristik UMKM yang lemah dalam pemanfaatan teknologi dan inovasi, lingkup pemasaran produk-produk UMKM di pasar domestik umumnya terbatas di wilayah UMKM tersebut berada, sehingga bantuan pemerintah akan sangat diperlukan dalam pembukaan aksesbagi UMKM.

Kemampuan UMKM untuk dapat bertahan dan tumbuh tergantung dari faktor internal dan eksternal. Faktor internal seperti skala usaha, stakeholders personality, latar belakang pendidikan, dan budaya perusahaan (pelatihan internal), dapat mempengaruhi tingkat produktivitas dan inovasi UMKM. Sedangkan faktor eksternal yaitu faktor- 
faktor di luar perusahaan seperti akses terhadap permodalan dan lingkungan kebijakan, baik kebijakan pemerintah ataupun kondisi ekonomi suatu negara, dan studi dari (Nicolescu, 2009) menyatakan bahwa faktor-faktor lingkungan internal dari UMKM itu lebih mempengaruhi kinerja daripada faktor lingkungan eksternal, namun tetap harus dipertimbangkan skala ekonomi dari UMKM tersebut. Partisipasi UMKM dalam pasar global juga masih rendah, hal ini diakibatkan oleh karena keterbatasan sumber daya seperti keuangan, informasi, kapasitas manajemen dan teknologi serta akses terhadap informasi pasar (Wignaraja, G., Jinjarak, 2015).

Permasalahan UMKM di Indonesia antara lain adalah kurangnya bahan baku yang mesti harus diimpor dari negara lain untuk proses produksi. pemasaran barang, permodalan, ketersediaan energi, infrastruktur dan informasi juga merupakan permasalahan yang sering muncul kemudian(Sudaryanto, R., \& Wijayanti, 2013).

Berdasarkan karekteristik yang ditetapkan oleh Bank Dunia, UMKM dikelompokkan menjadi tiga jenis, yaitu: 1. Usaha Mikro (jumlah karyawan 10 orang); 2. Usaha Kecil (jumlah karyawan 30 orang); dan 3.Usaha Menengah (jumlah karyawan hingga 300 orang).Pertumbuhan usaha mikro cukup signifikan, bila tahun2011 hanya mencapai 34,64\%, pada tahun 2012 berhasil meraih $38,81 \%$ terjadi peningkatan sebesar $4,17 \%$ (Bank Indonesia., 2016).

Meskipun pertumbuhan usaha mikro cukup menggembirakan namun kontribusi dan daya saing usaha mikro masih sangat rendah.Permasalahan mendasar yang dihadapi usaha mikro adalah kurangnya akses kepada sumber permodalan, pasar dan teknologi, serta organisasi usaha yang masih lemah.Berdasarkan catatan Bank Indonesia pada tahun 2014, dari 56,4 juta UMK yang ada di seluruh Indonesia, 70\% belum mampu mengakses pembiayaan melalui perbankan. Dan dari 30 persentase usaha mikro dan kecil yang mampu mengakses pembiayaan sebanyak $76,1 \%$ mendapatkan kredit dari bank dan 23,9\% mengakses dari non bank termasuk usaha simpan pinjam seperti koperasi (Bank Indonesia., 2016).

Untuk menjawab permasalahan keterbatasan modal, maka perlu lebih mengoptimalkan potensi lembaga keuangan yang dapat menjadi alternatif sumber dana bagi usaha mikro. Salah satu kelembagaan keuangan yang dapat dimanfaatkan dan didorong untuk membiayai kegiatan perekonomian di segmen mikro adalah Lembaga Keuangan Mikro (LKM).

Nasabah usaha mikro sering kali tidak memiliki jaminan, pendapatan tetap, dan administrasi yang dibuat cenderung hanya sesuai kebutuhan saja. Pelayanan keuangan mikro sebenarnya tidak hanya mencakup kredit mikro namun juga micro saving dan micro insurance atau asuransi mikro yang di Indonesia jarang dikenal.

Di Indonesia, institusi yang terlibat dalam keuangan mikro dapat dibagi menjadi tiga, yakni institusi bank, koperasi, serta non bank/non koperasi.Institusi bank termasuk di dalamnya bank umum, yang menyalurkan kredit mikro atau mempunyai unit mikro serta bank syariah dan unit syariah.

Lembaga Keuangan Mikro (LKM) merupakan salah satu penggerak roda perekonomian masyarakat dalam meningkatkan pendapatan, memperluas lapangan kerja, dan mengentaskan kemiskinan guna mewujudkan kesejahteraan masyarakat, serta memberikan kontribusi terhadap pendapatan daerah. Banyaknya jenis LKM yang tumbuh dan berkembang menunjukkan bahwa LKM sangat dibutuhkan oleh masyarakat, terutama kelompok masyarakat berpenghasilan rendah, pengusaha kecil dan 
mikro yang selama ini belum terjangkau oleh jasa pelayanan keuangan perbankan khususnya bank umum. Lembaga Keuangan Mikro (LKM) jika mengacu pada Undang Undang No.1 tahun 2013 tentang Lembaga Keuangan Mikro di definisikan sebagai lembaga keuangan yang khusus didirikan untuk memberikan jasa pengembangan usaha dan pemberdayaan masyarakat, baik melalui pinjaman atau pembiayaan dalam usaha skala mikro kepada anggota dan masyarakat, pengelolaan simpanan, maupun pemberian jasa konsultasi pengembangan usaha yang tidak semata-mata mencari keuntungan.

Menurut (Freddy Rangkuti, 2014) alat yang dipakai untuk menyusun faktor-faktor strategis perusahaan adalah matrik SWOT. Matrik ini dapat menggambarkan secara jelas bagaimana peluang dan ancaman eksternal yang dihadapi perusahaan dapat disesuaikan dengan kekuatan dan kelemahan yang dimilikinya. Matrik ini dapat menghasilkan empat set kemungkinan alternatif strategi.

Dari pokok permasalahan diatas, maka dapat di rumuskan pokok permasalahan yang dihadapi oleh usaha mikro tempe nasabah lembaga keuangan mikro adalah Bagaimana meningkatkan daya saing Usaha Mikro Tempe untuk keberlangsungan usaha di era persaingan MEA.Tujuan penelitian ini dilakukan adalah untuk mengkaji dan menentukan alternatif strategi daya saing Usaha Mikro Tempe yang telah mendapatkan pembiayaan dari LKM sehingga mampu menciptakan keberlangsungan usaha di era persaingan MEA ditengah maraknya impor kedelai. Dan memberi masukan kepada Lembaga Keuangan Mikro tentang strategi pembinaan usaha para pengusaha mikro produk tempe.

Beberapa hasil studi tentang usaha mikro dan lembaga keuangan mikro diantaranya:
Hasil Kajian (Sudaryanto, R., \& Wijayanti, 2013)tentang pemberdayaan UMKM menghadapi pasar bebas Asean menyatakan bahwa untuk mengembangkan strategi Usaha Mikro, Kecil, dan Menengah (UMKM) di Indonesia harus mendapat dukungan perbankan dalam penyaluran kredit. Dan skim kredit yang sangat familiar di masyarakat adalah Kredit Usaha Rakyat (KUR),yang khusus diperuntukkan bagi UMKM dengan kategori usaha layak, tanpa agunan. Kemudian penguatan lembaga pendamping UMKM dapat dilakukan melalui kemudahan akses serta peningkatan capacity building dalam bentuk pelatihan dan kegiatan penelitian yang menunjang pemberian kredit kepada UMKM.

(Suhartini, A. M. A., \& Yuta, 2012) meneliti tentang keterkaitan BPR sebagai LKM, UMK serta kemiskinan secara empiris di Indonesia tahun 2012, mengambil data sekunder dari 33 provinsi dengan menggunakan data sekunder, dan hasil analisisnya menunjukan bahwa keberadaan BPR dan UMK dapat membantu pengentasan kemiskinan. Pengaruh keberadaan BPR terhadap kemiskinan lebih kuat jika bekerja melalui keberadaan UMK.

(Holle, F. R., \& Dewi, 2014) melakukan pengembangan produksi industri kecil tahu di Desa Sepande Kecamatan Candi Kabupaten Sidoarjo. jenis penelitian deskriptif dengan pendekatan kualitatif, sehingga hasil penelitian akan diuraikan dan dianalisis sesuai dengan kondisi atau keadaan yang terjadi di lapangan. Hasil penelitian menyatakan Industri tahu di Desa Sepande terus berjalan karena diolah oleh sumber daya manusia yaitu pemilik industri tahu dan tenaga kerja yang berpengalaman dalam mengelola industri tahu. Serta ketersediaan bahan baku kedelai yang digunakan berkualitas yaitu kedelai import sehingga tahu yang dihasilkan berkualitas, 
Hasil penelitian (Nursiah, T., Kusnadi, N., \& Burhanuddin, 2015) menunjukan bahwa pengrajin tempe di Bogor yang memiliki karakteristik wirausaha rendah,tidak berani dalam mengambil risiko puas dengan penghasilan yang diperoleh dan hanya berorientasi pada pemenuhan penghasilan untuk kebutuhan keluarga saja.

\section{METODE PENELITIAN}

Penelitian ini dilakukan dengan pendekatan mix methode (metode campuran). Metode penelitian campuran adalah metodologi untuk melakukan penelitian yang melibatkan pengumpulan, menganalisis, dan mengintegrasikan kuantitatif dan penelitian kualitatif mengingat tujuan dari penelitian ini adalah menemukan alternatif solusi daya saing usaha mikro dan LKM. Jenis data yang digunakan dalam penelitian ini adalah data primer dan data sekunder. Data primer yang dibutuhkan dalam penelitian ini diperolehmelalui hasil wawancara mendalam dengan pelaku usaha mikro produk tempe di kabupaten Sidoarjo, dan berbagai pihak yang telah dipilih menjadi narasumber. Sedangkan Data sekunder yang digunakan dalam penelitian ini diperoleh dariliteratur, publikasi ilmiah yang berkaitan dengan UMKM serta dari instansi terkaitseperti dinas Koperasi dan UMKM, dinas Perindustrian dan Perdagangan Propinsi Jatim, serta Badan Pusat Statistik (BPS). Jumlah populasi dalam penelitian ini adalah para pengusaha tempe di desa sepande kecamatan candi kabupaten sidoarjo yang berjumlah 228 pengrajin tempe yang tidak tergabung dalam anggota koperasi. Namun jumlah pengrajin tempe yang telah mendapat pembiayaan dari LKM belum dapat diketahui dengan pasti, sehingga penelitian ini menggunakan narasumber pengusaha tempe yang telah mendapatkan pembiayaan LKM. Penentuan narasumber dalam penelitian ini menggunakan metode pengamatan, karena menurut (Lincoln, 1995) tidak ada satu rumuspun yang dapat menentukan ukuran sampel secara paling tepat dan tidak ada pula aturan yang dapat menjelaskan dengan tegas antara sampel besar dan sampel kecil adalah pengusaha mikro produk tempe di wilayah kabupaten Sidoarjo yang telah menjadi nasabah Lembaga Keuangan Mikro berjumlah 10 orang. Variabel penelitian terdiri dari Lingkungan Internal dan Lingkungan Eksternal yang digunakan ditentukan berdasarkan hasil wawancara dengan 10 pengusaha mikro produk tempe yang telah mendapatkan pembiayaan dari lembaga Kredit Usaha Rakyat Kecil (KURK). Variabel lingkungan internal yang dirumuskan melalui hasil wawancara terdiri atas aspek produksi, sumber daya manusia, pemasaran, keuangan, dan suplier bahan baku dari 10 pengusaha mikro tempe di Sidoarjo.Sedangkan variabel lingkungan eksternal terdiri atas pesaing, kondisi perekonomian, politik, kebijakan pemerintah, sosial budaya, dan teknologi. Penentuan nilai rating berdasarkan pada persepsi responden terhadap faktor-faktor lingkungan strategis dengan skala 1- 4 dimana nilai 1 untuk faktor yang dianggap kurang/kecil, nilai dua untuk faktor yang dianggap cukup/sedang, nilai 3 untuk yang dianggap baik/besar dan nilai 4 yang dianggap sangat baik/sangat besar.

Pemilihan responden menggunakan cara purposive sampling yakni teknik pengambilan sampel sumber data dengan pertimbangan tertentu (Sugiyono, 2009).

Untuk mengetahui pendapat masing-masing responden mengenai tingkat kepentingan variabel satu dengan yang lain diukur berdasarkan preferensi yang diberikan responden secara subyektif terhadap kepentingan suatu faktor terhadap faktor lainnya 
atau suatu sub faktornya terhadap sub faktor lainnya dalam nilai skala 1-3 kemudian menjadi bobot dari tiap-tiap kriteria dalam faktor-faktor eksternal dan internal usaha mikro tempe maka metode kuisioner yang berupa matrik perbandingan berpasangan digunakan. Pemberian nilai diberikan berdasarkan pada perbandingan berpasangan antara 2 faktor secara relatif berdasarkan kepentingan atau pengaruhnya terhadap pengusaha mikro produk tempe. Penentuan rating dan bobot dimodifikasi dari model tahapan dalam mengidentifikasi faktorfaktor lingkungan internal dalam matriks IFE dan EFE (David, 2006). Cara membaca perbandingan dimulai dari variabel atau faktor-faktor penentu pada baris 1 (huruf cetak miring) terhadap kolom 1 (huruf cetak tegak) dan harus konsisten atau teratur. Nilai 1 diberikan jika indikator horizontal kurang penting daripada indikator vertikal., Nilai 2 diberikan jika indikator horizontal sama penting daripada indikator vertikal., sedangkan nilai 3 diberikan jika indikator horizontal lebih penting daripada indikator vertikal. Skor adalah rating dikalikan dengan rating/peringkat untuk masingmasing variabel.

Metode analisis yang digunakan dalam penelitian ini adalah Analisis SWOT yang mengidentifikasi aspek positif, yaitu strength (kekuatan) dan aspek negatif, yaitu weakness (kelemahan) dari internal organisasi. Sedangkan dari eksternal organisasi/ BPR Surabaya dilakukan identifikasi opportunities (peluang) dan threat (ancaman) yang dimiliki Usaha Mikro produk tempe. Hasil analisis SWOT dan matrik SWOT kemudian dilanjutkan dengan QSPM (Quantitative Strategic Planning Matrix) yang dijadikan sebagai dasar untuk mengetahui prioritas strategi yang akan digunakan. Berdasarkan matriks QSPM ditentukan alternatif strateginya dimana menurut (David, 2006) alternatif strategi yang paling baik adalah yang memiliki nilai total terbesar.

\section{HASIL DAN PEMBAHASAN}

Profi pengusaha mikro produk tempe di Sidoarjo.

Pengusaha mikro produk tempe di Sidoarjo, rata-rata adalah usaha keluarga dan turun temurun dimana pemilik rata-rata adalah kepala keluarga dan memiliki jumlah tenaga kerja berkisar 1 sampai 4 orang dan kebanyakan masih memiliki hubungan keluarga.Lokasi usaha ada ditempat tinggal dan hampir semua tidak memiliki ijin usaha. Tidak memiliki pengolahan limbah, dan proses pembersihan kedelai biasanya dilakukan di sungai atau sumur. Besaran kuantitas, jenis dan kualitas tempenya didasarkan atas pesanan saja, beberapa memproduksi lebih banyak dari pesanan tetapi besarannya tidak lebih dari $10 \%$.

Untuk menentukan faktor-faktor strategis pada lingkungan internal dan eksternal dilakukan melalui wawancara, sedangkan pemilihan elemennya didasarkan pada konsep dan teori dari (Wheelen, T. L., \& Hunger, 2011) yang menyatakan lingkungan internal perusahaan adalah sumberdaya perusahaan yang menentukan kekuatan dan kelemahan perusahaan. Berdasarkan hal tersebut maka dirumuskan elemen-elemen faktor lingkungan internal yang kemudian di tanyakan kepada para pengusaha mikro produk tempe yang menghasilkan rumusan lingkungan internal sebagai berikut :

1. SDM yang murah

2. Ongkos produksi murah

3. Memiliki pelanggan tetap

4. Lokasi usaha yang dekat dengan sumber air.

5. Modal usaha terbatas

6. Beban biaya bunga

7. Harga kedelai tidak stabil

8. Kuantitas produk terbatas 
9. Kualitas produk tidak standar

10. Teknologi produksi sangat tradisional

\section{Analisis Faktor Lingkungan Internal}

Tabel 1

Hasil Rekapitulasi Rating Faktor Lingkungan Internal

\begin{tabular}{|c|l|c|}
\hline No & \multicolumn{1}{|c|}{ Faktor Internal } & $\begin{array}{c}\text { Median } \\
\text { (yang sering } \\
\text { muncul) }\end{array}$ \\
\hline & Kekuatan & \\
\hline 1 & SDM yang murah & 4 \\
\hline 2 & Ongkos produksi murah & 3 \\
\hline 3 & Memiliki pelanggan & 4 \\
\hline 4 & $\begin{array}{l}\text { Lokasi usaha yang dekat } \\
\text { dengan sumber air. }\end{array}$ & 3 \\
\hline & Kelemahan & 2 \\
\hline 1 & Modal usaha terbatas & 4 \\
\hline 2 & Beban biaya bunga & 2 \\
\hline 3 & Teknologi tradisional & 2 \\
\hline 4 & Kuantitas produk & 2 \\
\hline 5 & $\begin{array}{l}\text { Kualitas produk tidak } \\
\text { standar }\end{array}$ & $\begin{array}{l}\text { Biaya bahan baku } \\
\text { kedelai }\end{array}$ \\
\hline 6 & \multicolumn{2}{|l}{} \\
\hline
\end{tabular}

Berdasarkan tabel 1 dapat terlihat bahwa median yang sering muncul bernilai 4 untuk faktor internal kekuatan ada pada faktor SDM yang murah,danmemiliki pelanggan tetap. Sedangkan untuk faktor internal kelemahan median yang sering muncul dan bernilai 4 ada pada beban biaya bunga dan Biaya bahan baku kedelai.

Tabel 2 Kode Matrik Faktor Internal

\begin{tabular}{|c|l|c|}
\hline No & \multicolumn{1}{|c|}{ Faktor Internal } & kode \\
\hline 1 & SDM yang murah & $A$ \\
\hline 2 & Ongkos produksi murah & $B$ \\
\hline 3 & Memiliki pelanggan tetap & $C$ \\
\hline 4 & $\begin{array}{l}\text { Lokasi usaha yang dekat } \\
\text { dengan sumber air. }\end{array}$ & $D$ \\
\hline 5 & Modal usaha terbatas & $E$ \\
\hline 6 & Beban biaya bunga & $F$ \\
\hline 7 & Teknologi tradisional & $G$ \\
\hline
\end{tabular}

\begin{tabular}{|c|l|c|}
\hline 8 & Kuantitas produk terbatas & $H$ \\
\hline 9 & Kualitas produk tidak standar & $I$ \\
\hline 10 & Biaya bahan baku kedelai & $J$ \\
\hline
\end{tabular}

Tabel 3

Pengolahan Matrik Perbandingan Bobot Faktor Internal

\begin{tabular}{|c|c|c|c|c|c|c|c|c|c|c|c|c|}
\hline Faktor & A & B & C & D & E & F & G & H & I & J & Total & Bobot \\
\hline A & 0 & 2 & 3 & 1 & 3 & 3 & 1 & 3 & 3 & 3 & 22 & 0,118 \\
\hline B & 2 & 0 & 3 & 2 & 3 & 3 & 2 & 2 & 3 & 2 & 22 & 0,118 \\
\hline C & 1 & 1 & 0 & 2 & 3 & 3 & 2 & 2 & 2 & 2 & 18 & 0,096 \\
\hline D & 1 & 2 & 1 & 0 & 3 & 3 & 2 & 2 & 1 & 2 & 17 & 0,091 \\
\hline E & 1 & 3 & 2 & 2 & 0 & 1 & 1 & 1 & 1 & 1 & 13 & 0,070 \\
\hline F & 2 & 1 & 2 & 2 & 3 & 0 & 1 & 2 & 1 & 2 & 16 & 0,086 \\
\hline G & 1 & 2 & 3 & 2 & 2 & 1 & 0 & 3 & 1 & 1 & 16 & 0,086 \\
\hline H & 2 & 2 & 3 & 3 & 1 & 2 & 3 & 0 & 1 & 1 & 18 & 0,096 \\
\hline I & 2 & 1 & 2 & 3 & 1 & 2 & 2 & 3 & 0 & 3 & 19 & 0,102 \\
\hline J & 3 & 3 & 3 & 3 & 3 & 2 & 3 & 3 & 3 & 0 & 26 & 0,139 \\
\hline \multicolumn{1}{r}{} & & & & & & & & 187 & 1,000 \\
\hline
\end{tabular}

Pada tabel 3 pengolahan matrik perbandingan bobot faktor internal, terlihat bahwa bobot tertinggi ada pada harga kedelai tidak stabil sebesar 0,139 dan bobot terendah ada pada modal usaha terbatas sebesar 0,07 .

Tabel 4

Matrik IFE untuk usaha mikro Tempe

\begin{tabular}{|c|l|c|c|c|}
\hline No & \multicolumn{1}{|c|}{ Faktor Internal } & Rating & Bobot & Skor \\
\hline & Kekuatan & & & \\
\hline 1 & SDM yang murah & 4 & 0,118 & 0,472 \\
\hline 2 & Ongkos produksi & 3 & 0,118 & 0,354 \\
\hline 3 & Memiliki pelanggan & 4 & 0,096 & 0,384 \\
\hline 4 & $\begin{array}{l}\text { Lokasi usaha yang } \\
\text { dekat dengan } \\
\text { sumber air. }\end{array}$ & 3 & 0,091 & 0,273 \\
\hline & Kelemahan & & & \\
\hline 1 & $\begin{array}{l}\text { Modal usaha } \\
\text { terbatas }\end{array}$ & 2 & 0,070 & 0,140 \\
\hline 2 & $\begin{array}{l}\text { Beban biaya bunga } \\
3\end{array}$ & 4 & 0,086 & 0,334 \\
\hline 4 & $\begin{array}{l}\text { Teknologi } \\
\text { Kuantitas produk } \\
\text { terbatas }\end{array}$ & 2 & 0,086 & 0,172 \\
\hline 5 & $\begin{array}{l}\text { Kualitas produk } \\
\text { tidak standar }\end{array}$ & 2 & 0,102 & 0,192 \\
\hline
\end{tabular}




\begin{tabular}{|c|l|c|c|c|}
\hline 6 & $\begin{array}{l}\text { Biaya bahan baku } \\
\text { kedelai }\end{array}$ & 4 & 0,139 & 0,556 \\
\hline \multicolumn{2}{|c|}{ Total } & & $\mathbf{1 , 0 0 0}$ & $\mathbf{3 , 0 8 1}$ \\
\hline
\end{tabular}

Pada tabel 4 terlihat bahwa skor tertinggi untuk kekuatan ada pada SDM yang murah. Sedangkan pada kelemahan yang tertinggi ada pada biaya bahan baku kedelai. Dengan total skor pembobotan faktor internal sebesar 3,081 (lebih besar dari 2,5) menunjukkan bahwa kekuatan usaha mikro tempe lebih dominan daripada kelemahan yang dimilikinya.

\section{Analisis Faktor Lingkungan Eksternal}

Tabel 5

Hasil Rekaapitulasi Rating Faktor Eksternal

\begin{tabular}{|c|c|c|}
\hline No & Faktor Eksternal & $\begin{array}{l}\text { Median } \\
\text { (yang sering } \\
\text { muncul) }\end{array}$ \\
\hline & Peluang & \\
\hline 1 & $\begin{array}{l}\text { Maraknya usaha gorengan } \\
\text { dan tempe penyet }\end{array}$ & 4 \\
\hline 2 & $\begin{array}{l}\text { Meningkatnya permintaan } \\
\text { produk tempe dengan } \\
\text { ukuran khusus. }\end{array}$ & 3 \\
\hline 3 & $\begin{array}{l}\text { Adanya program bantuan } \\
\text { dari pemerintah. }\end{array}$ & 3 \\
\hline 4 & $\begin{array}{l}\text { Pelanggan melakukan } \\
\text { hubungan yang baik }\end{array}$ & 4 \\
\hline 5 & $\begin{array}{l}\text { Kemajuan teknologi } \mathrm{HP} \\
\text { dengan WA jadi media }\end{array}$ & 4 \\
\hline \multirow[t]{2}{*}{6} & $\begin{array}{l}\text { Adanya LKM yang } \\
\text { membantu permodalan }\end{array}$ & 4 \\
\hline & Ancaman & \\
\hline 1 & $\begin{array}{ll}\text { Beredarnya } & \text { duplikasi } \\
\text { produk tempe } & \text { kemasan } \\
\text { plastik } & \end{array}$ & 1 \\
\hline 2 & $\begin{array}{lcc}\text { Tingkat } & \text { suku } & \text { bunga } \\
\text { pinjaman } & \text { yang } & \text { relatif }\end{array}$ & 4 \\
\hline 3 & $\begin{array}{lr}\text { Kebijakan } & \text { pemerintah } \\
\text { (meningkatnya } & \text { harga } \\
\text { BBM). } & \\
\end{array}$ & 3 \\
\hline 4 & Perdagangan bebas (AFTA) & 2 \\
\hline 5 & $\begin{array}{l}\text { Suplai dan Harga kedelai } \\
\text { yang tidak stabil (impor } \\
\text { kedelai) }\end{array}$ & 4 \\
\hline
\end{tabular}

Pada tabel 5 dapat dilihat untuk faktor lingkungan eksternal median yang sering muncul dan bernilai 4 adalah pada faktor pasar, pelanggan, dan sumber pembiayaan. Sedangkan untuk ancaman ada pada tingkat suku bunga pinjaman dan Suplai dan Harga kedelai yang tidak stabil (impor kedelai).

Tabel 6 Kode Matrik Faktor Eksternal

\begin{tabular}{|c|l|c|}
\hline No & \multicolumn{1}{|c|}{ Faktor Eksternal } & Kode \\
\hline 1 & $\begin{array}{l}\text { Maraknya usaha gorengan dan } \\
\text { tempe penyet }\end{array}$ & $A$ \\
\hline 2 & $\begin{array}{l}\text { Meningkatnya permintaan produk } \\
\text { tempe dengan ukuran khusus. }\end{array}$ & $B$ \\
\hline 3 & $\begin{array}{l}\text { Adanya program bantuan dari } \\
\text { pemerintah. }\end{array}$ & $C$ \\
\hline 4 & $\begin{array}{l}\text { Pelanggan melakukan hubungan } \\
\text { yang baik }\end{array}$ & $D$ \\
\hline 5 & $\begin{array}{l}\text { Kemajuan teknologi HP dengan } \\
\text { WA iadi media promosi }\end{array}$ & $E$ \\
\hline 6 & $\begin{array}{l}\text { Adanya LKM yang membantu } \\
\text { permodalan }\end{array}$ & $F$ \\
\hline 7 & $\begin{array}{l}\text { Beredarnya duplikasi produk tempe } \\
\text { kemasan plastik dan corak batik } \\
\text { tiruan }\end{array}$ & $G$ \\
\hline 8 & $\begin{array}{l}\text { Tingkat suku bunga pinjaman yang } \\
\text { relatif tinggi }\end{array}$ & $H$ \\
\hline 9 & $\begin{array}{l}\text { Kebijakan pemerintah (mening- } \\
\text { katnya harga BBM). }\end{array}$ & $I$ \\
\hline 10 & \begin{tabular}{l} 
Perdagangan bebas (AFTA) \\
\hline 11
\end{tabular} & $\begin{array}{l}\text { Sarana dan prasarana transportasi } \\
\text { yang buruk. }\end{array}$ \\
\hline
\end{tabular}

Tabel 6 di atas merupakan pengkodean faktor eksternal untuk memudahkan dalam melakukan proses berpasangan antar faktor eksternal, memilih dan menilai faktor mana yang memiliki keterkaitan. Pemberian nilai diberikan berdasarkan pada perbandingan berpasangan antara 2 faktor secara relatif berdasarkan kepentingan atau pengaruhnya terhadap keberlangsungan usaha dari pengusaha mikroproduk Tempe. Setelah semua kuisioner terkumpul, matrik perbandingan berpasangan tersebut kemudian diolah untuk dilakukan rekapitulasi terhadap 
seluruh responden dan menentukan skor dari lingkungan eksternal.

\section{Tabel 7}

Pengolahan Matrik Perbandingan Bobot Faktor Ekternal

\begin{tabular}{|c|c|c|c|c|c|c|c|c|c|c|c|c|c|}
\hline Faktor & $\mathrm{A}$ & $\mathrm{B}$ & $\mathrm{C}$ & $\mathrm{D}$ & $\mathrm{E}$ & $\mathrm{F}$ & $\mathrm{G}$ & $\mathrm{H}$ & $\mathrm{I}$ & $\mathrm{J}$ & $\mathrm{K}$ & Total & Bobot \\
\hline $\mathrm{A}$ & 0 & 1 & 1 & 1 & 1 & 1 & 3 & 2 & 2 & 3 & 1 & 16 & 0,084 \\
\hline $\mathrm{B}$ & 2 & 0 & 3 & 1 & 1 & 1 & 3 & 3 & 3 & 3 & 1 & 21 & 0,087 \\
\hline $\mathrm{C}$ & 2 & 1 & 0 & 1 & 1 & 1 & 3 & 3 & 3 & 3 & 1 & 19 & 0,088 \\
\hline $\mathrm{D}$ & 3 & 2 & 2 & 0 & 1 & 1 & 3 & 3 & 3 & 3 & 1 & 22 & 0,102 \\
\hline $\mathrm{E}$ & 1 & 2 & 3 & 2 & 0 & 1 & 3 & 3 & 3 & 3 & 1 & 22 & 0,102 \\
\hline $\mathrm{F}$ & 2 & 1 & 3 & 2 & 3 & 0 & 3 & 3 & 3 & 3 & 1 & 24 & 0,111 \\
\hline $\mathrm{G}$ & 1 & 3 & 2 & 3 & 2 & 1 & 0 & 2 & 1 & 2 & 1 & 18 & 0,083 \\
\hline $\mathrm{H}$ & 3 & 3 & 2 & 3 & 1 & 2 & 2 & 0 & 1 & 2 & 1 & 20 & 0,093 \\
\hline $\mathrm{I}$ & 3 & 3 & 2 & 2 & 1 & 2 & 2 & 1 & 0 & 2 & 1 & 19 & 0,088 \\
\hline $\mathrm{J}$ & 3 & 1 & 3 & 2 & 1 & 2 & 1 & 1 & 2 & 0 & 1 & 17 & 0,079 \\
\hline $\mathrm{K}$ & 1 & 1 & 3 & 2 & 1 & 2 & 1 & 1 & 3 & 3 & 0 & 18 & 0,083 \\
\hline & & & & & & & & & 216 & 1,000 \\
\hline
\end{tabular}

Dari tabel 7 terlihat bahwa bobot faktor eksternal yang terbesar ada pada adanya LKM yang membantu permodalan yakni sebesar 111. Hal ini menunjukan bahwa keberadaan LKM selama ini dirasakan sangat membantu kegiatan usaha produksi tempe pengusaha mikro di kabupaten Sidoarjo. Sedangkan bobot terendah ada pada perdagangan bebas AFTA, pemahaman para pengusaha mikro tempe terhadap AFTA yang rendah membuat mereka tidak terlalu menghiraukan adanya perdagangan bebas AFTA sehingga memiliki bobot yang rendah.

Pada tabel 8 terlihat bahwa skor tertinggi untuk peluang ada pada adanya LKM yang membantu permodalan dengan skor 0,444. Sedangkan pada Ancaman yang tertinggi ada pada tingkat suku bunga pinjaman yang relatif tinggi dengan skor 0,332.Dengan total skor pembobotan faktor eksternal sebesar 3,081 (lebih besar dari 2,5) menunjukkan bahwa kekuatan usaha mikro tempe lebih dominan daripada kelemahan yang dimilikinya.
Tabel 8

Matrik EFE untuk Usaha Mikro Produk Tempe Kabupaten Sidoarjo

\begin{tabular}{|c|c|c|c|c|}
\hline No & Faktor Eksternal & Ratin & Bobot & Skor \\
\hline & Peluang & & & \\
\hline 1 & $\begin{array}{lr}\text { Maraknya } & \text { usaha } \\
\text { gorengan } & \text { dan } \\
\text { tempe penyet } & \end{array}$ & 4 & 0,084 & 0,33 \\
\hline 2 & $\begin{array}{l}\text { Meningkatnya per- } \\
\text { mintaan produk } \\
\text { tempe dengan } \\
\text { ukuran khusus. }\end{array}$ & 3 & 0,087 & 0,261 \\
\hline 3 & $\begin{array}{lr}\text { Adanya } & \text { program } \\
\text { bantuan } & \text { dari } \\
\text { pemerintah. } & \\
\end{array}$ & 3 & 0,088 & 0,26 \\
\hline 4 & $\begin{array}{l}\text { Pelanggan mela- } \\
\text { kukan hubungan } \\
\text { yang baik }\end{array}$ & 4 & 0,102 & 0,40 \\
\hline 5 & $\begin{array}{l}\text { Kemajuan teknolo- } \\
\text { gi HP dengan WA } \\
\text { jadi media promosi }\end{array}$ & 4 & 0,102 & 0,40 \\
\hline 6 & $\begin{array}{l}\text { Adanya LKM yang } \\
\text { membantu permo- } \\
\text { dalan }\end{array}$ & 4 & 0,111 & 0,44 \\
\hline & Ancaman & & & \\
\hline 1 & $\begin{array}{l}\text { Beredarnya dupli- } \\
\text { kasi produk tempe } \\
\text { kemasan plastik }\end{array}$ & 1 & 0,111 & 0,111 \\
\hline 2 & $\begin{array}{l}\text { Tingkat suku bunga } \\
\text { pinjaman yang } \\
\text { relatif tinggi }\end{array}$ & 4 & 0,083 & 0,332 \\
\hline 3 & $\begin{array}{l}\text { Kebijakan peme- } \\
\text { rintah (meningkat- } \\
\text { nya harga BBM). }\end{array}$ & 3 & 0,093 & 0,279 \\
\hline 4 & $\begin{array}{l}\text { Perdagangan bebas } \\
\text { (AFTA) }\end{array}$ & 2 & 0,088 & 0,176 \\
\hline 5 & 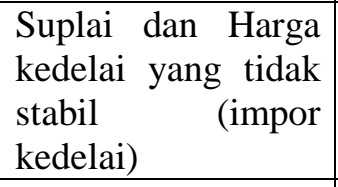 & 4 & 0,079 & 0,316 \\
\hline & Total & & 1,000 & 3,335 \\
\hline
\end{tabular}

\section{Matrik Faktor Internal Ekternal (IE)}

Berdasarkan matrik IFE yang menunjukan skor sebesar 3,081 dan Matrik EFE yang menunjukan skor sebesar 3,335 maka dibuatlah matrik faktor internal ekternal untuk mengetahui posisi strategi apa yang harus dilakukan oleh pengusaha mikro produk tempe di Sidoarjo. 
Total Nilai IFE Yang Diberi Bobot

\begin{tabular}{|c|c|c|c|}
\hline & $\begin{array}{c}\text { Kuat } \\
3-4\end{array}$ & $\begin{array}{l}\text { Sedang } \\
2-2,99\end{array}$ & $\begin{array}{c}\text { Lemah } \\
1-1,99\end{array}$ \\
\hline $\begin{array}{c}\text { Tinggi } \\
3-4\end{array}$ & $\begin{array}{c}\text { I } \\
\text { Tumbuh } \\
\text { dan } \\
\text { kembangkan }\end{array}$ & $\begin{array}{c}\text { II } \\
\text { Tumbuh } \\
\text { dan } \\
\text { kembangkan }\end{array}$ & $\begin{array}{c}\text { III } \\
\text { Jaga } \\
\text { dan } \\
\text { pertahankan }\end{array}$ \\
\hline $\begin{array}{l}\text { Sedang } \\
2-2,99\end{array}$ & $\begin{array}{c}\text { IV } \\
\text { Tumbuh dan } \\
\text { kembangkan }\end{array}$ & $\begin{array}{c}\mathbf{V} \\
\text { Jaga dan } \\
\text { pertahankan }\end{array}$ & $\begin{array}{c}\text { VI } \\
\text { Panen atau } \\
\text { divestasi }\end{array}$ \\
\hline $\begin{array}{l}\text { Rendah } \\
1-1,99\end{array}$ & $\begin{array}{c}\text { VII } \\
\text { Jaga dan } \\
\text { pertahankan }\end{array}$ & $\begin{array}{c}\text { VIII } \\
\text { Panen atau } \\
\text { divestasi }\end{array}$ & $\begin{array}{c}\text { IX } \\
\text { Panen atau } \\
\text { divestasi }\end{array}$ \\
\hline
\end{tabular}

Gambar 1. Matrik IE

Sumber: Di adopsi dari David, F. R. (2006).

Pada gambar 1 dapat dilihat hasil pencocokan strategi umum menggunakan matrik IE menunjukkan bahwa usaha mikro tempe saat ini berada di kuadran 1(satu), dimana strategi umum yang tepat untuk dilakukan oleh pengusaha mikro tempe Kabupaten Sidoarjo adalah Tumbuh dan Kembangkan.

Menurut David, F. R. (2006) Pada sel 1 (tumbuh dan kembangkan) pilihan strategi yang intensif (penetrasi pasar, pengembangan pasar, dan pengembangan produk) atau integratif (integrasi ke belakang, integrasi ke depan dan integrasi horizontal) bisa menjadi pilihan yang paling tepat umtuk dapat meningkatkan daya saing pengusaha mikro produk tempe kabupaten Sidoarjo. Berdasarkan data matrik IE tersebut kemudian dinyatakan dalam bentuk pertanyaan wawancara kepada para nara sumber untuk dibuat alternatif strateginya yang hasil rumusan strateginya sebagai berikut:

Strategi 1 : Penetrasi pasar melalui pengoptimalan pemanfaatan Whatsaap (WA) Messenger dengan membuat WA group sebagai media promosi produk tempe Sidoarjo.

Strategi 2 : Pengembangan pasar dimana tidak hanya melayani pelanggan tetap saja yang rata-rata adalah pedagang sayur dan makanan tetapi juga melayani pembeli langsung khususnya kalangan menengah.

Strategi 3 : Pengembangan produk dimana produk tempe dikembangkan jenis dan variannya khususnya pada bentuk dan kemasan yang lebih menarik agar dapat menciptakan nilai tambah dan harga jual.

Strategi 4 : Integrasi kebelakang, dengan melakukan kerjasama para pengusaha tempe untuk melakukan pembelian secara bersama produk kedelai sehingga skala pembelian meningkat yang akan menurunkan harga beli perunit.

Kemudian, alternatif strategi ini dianalisa mengenai pengaruhnya terhadap faktor internal (kekuatan dan kelemahan) serta faktor eksternal (peluang dan ancaman). Dalam pengisian matrik QSPM, dilakukan wawancara serta diskusi dengan responden yang dianggap memiliki kapabilitas serta pengetahuan terkait strategi perusahaan. Skor daya tarik diberikan pada tiap strategi untuk menunjukkan daya tarik relatif satu strategi atas strategi yang lain. Kisaran skor daya tarik dalam QSPM adalah; 1 = tidak memiliki daya tarik., 2 = daya tariknya rendah., 3 = daya tariknya sedang., 4 = daya tariknya tinggi. 
Tabel 9

Matrik QSPM untuk usaha mikro tempe Kabupaten Sidoarjo

\begin{tabular}{|c|c|c|c|c|c|c|c|c|c|}
\hline \multirow{3}{*}{$\begin{array}{l}\text { Faktor } \\
\text { Penentu } \\
\text { Strategis }\end{array}$} & \multicolumn{9}{|c|}{ Alternatif Strategi Pilihan } \\
\hline & \multirow[t]{2}{*}{ Bobot } & \multicolumn{2}{|c|}{$\begin{array}{l}\text { 1. Penetrasi } \\
\text { Pasar }\end{array}$} & \multicolumn{2}{|c|}{$\begin{array}{l}\text { 2. Pengem- } \\
\text { bangan Pasar }\end{array}$} & \multicolumn{2}{|c|}{$\begin{array}{c}\text { 3. Pengem- } \\
\text { bangan Produk }\end{array}$} & \multicolumn{2}{|c|}{$\begin{array}{l}\text { 4. Integrasi } \\
\text { Kebelakang }\end{array}$} \\
\hline & & AS & TAS & AS & TAS & $\mathbf{A S}$ & TAS & $\mathbf{A S}$ & TAS \\
\hline \multicolumn{10}{|l|}{ Kekuatan } \\
\hline 1 & 0,118 & 2 & 0,116 & 1 & 0,058 & 4 & 0,472 & 3 & 0,174 \\
\hline 2 & 0,118 & - & - & - & - & 3 & 0,354 & - & \\
\hline 3 & 0,096 & 1 & 0,053 & 3 & 0,159 & 4 & 0,384 & 2 & 0,106 \\
\hline 4 & 0,091 & - & - & - & - & 3 & 0,273 & - & - \\
\hline \multicolumn{10}{|l|}{ Kelemahan } \\
\hline 1 & 0,070 & 1 & 0,046 & 4 & 0,184 & 2 & 0,140 & 2 & 0,092 \\
\hline 2 & 0,086 & - & - & - & - & 2 & 0,172 & - & - \\
\hline 3 & 0,086 & - & - & - & - & 2 & 0,172 & - & - \\
\hline 4 & 0,096 & 2 & 0,086 & 4 & 0,172 & 2 & 0,192 & 3 & 0,129 \\
\hline 5 & 0,102 & 1 & 0,044 & 3 & 0,132 & 4 & 0,408 & 4 & 0,176 \\
\hline 6 & 0,139 & 1 & 0,042 & 3 & 0,126 & 2 & 0,278 & 4 & 0,168 \\
\hline \multicolumn{10}{|l|}{ Peluang } \\
\hline 1 & 0,084 & 1 & 0,069 & 4 & 0,276 & 4 & 0,336 & 2 & 0,138 \\
\hline 2 & 0,087 & 1 & 0,063 & 4 & 0,252 & 3 & 0,261 & 2 & 0,126 \\
\hline 3 & 0,088 & - & - & - & - & 3 & 0,264 & - & \\
\hline 4 & 0,102 & - & - & - & - & 4 & 0,408 & - & - \\
\hline 5 & 0,102 & 1 & 0,047 & 3 & 0,141 & 4 & 0,408 & 4 & 0,188 \\
\hline 6 & 0,111 & 1 & 0,062 & 4 & 0,248 & 4 & 0,444 & 3 & 0,186 \\
\hline \multicolumn{10}{|l|}{ Ancaman } \\
\hline 1 & 0,083 & 2 & 0,130 & 4 & 0,260 & 1 & 0,111 & 3 & 0,195 \\
\hline 2 & 0,093 & 2 & 0,120 & 4 & 0,240 & 2 & 0,166 & 1 & 0,060 \\
\hline 3 & 0,088 & 2 & 0,126 & 3 & 0,189 & 3 & 0,279 & 1 & 0,063 \\
\hline 4 & 0,079 & - & - & - & - & 2 & 0,176 & - & - \\
\hline 5 & 0,083 & - & - & - & - & 1 & 0,079 & - & - \\
\hline $\begin{array}{l}\text { Total Nilai } \\
\text { Daya Tarik }\end{array}$ & & & 1,004 & & 2,437 & & 5,777 & & 1,801 \\
\hline
\end{tabular}

Alternatif strategi yang memiliki total nilai daya tarik tertinggi adalah strategi nomer 3, hal ini menunjukkan bahwa untuk meningkatkan daya saing usaha mikro tempenasabah lembaga keuangan mikro di Kabupaten Sidoarjo maka harus dilakukan strategi pengembangan produk melalui pengembangan jenis dan variannya khususnya pada bentuk dan kemasan yang lebih menarik agar dapat menciptakan nilai tambah dan harga jual.

Berdasarkan urutan peringkat daya tariknya, alternatif strategi yang dapat diimplementasikan oleh usaha mikro tempe nasabah lembaga keuangan mikro di Kabupaten Sidoarjo adalah :

Prioritas Strategi 1 (Skor QSPM=5,777): Pengembangan produk dimana produk tempe dikembangkan jenis dan variannya khususnya pada bentuk dan kemasan yang lebih menarik agar dapat menciptakan nilai tambah dan harga jual.

Prioritas Strategi 2 (Skor QSPM=2,473):

Pengembangan pasar dengan tidak hanya melayani pelanggan tetap saja yang rata-rata adalah pedagang sayur dan makanan tetapi juga melayani pembeli langsung khususnya kalangan menengah. 
Prioritas Strategi 3 (Skor QSPM=1,081): Integrasi kebelakang, dengan melakukan kerjasama para pengusaha tempe untuk melakukan pembelian secara bersama produk kedelai sehingga skala pembelian meningkat yang akan menurunkan harga beli perunit.

\section{Prioritas Strategi 4 (Skor QSPM=1,004):}

Penetrasi pasar melalui pengoptimalan pemanfaatan Whatsaap (WA) Messenger dengan membuat WA group sebagai media promosi produk tempe Sidoarjo.

Secara garis besar strategi peningkatan daya saing usaha mikro tempe nasabah lembaga keuangan mikro di Kabupaten Sidoarjo sebagai berikut : melakukan pengembangan jenis dan varian produk tempe khususnya perubahan bentuk dan kemasan yang lebih menarik dan hiegenis sehingga dapat memberi nilai tambah produk dan meningkatkan harga jual, yang pada akhirnya akan meningkatkan keuntungan usaha dan dapat mengatasi kelemahan pada beban biaya bunga kredit yang diberikan oleh lembaga keuangan mikro. Kemudian produk tempe tersebut dipasarkan langsung ke pelanggan menengah dimana di Kabupaten Sidoarjo banyak perumahan yang di huni oleh kelas menengah dengan melakukan promosi melalui group WA takeline yang bisa dikembangkan adalah Produk Tempe Asli Sidoarjo Enak dan Higienis).

\section{PENUTUP}

\section{Simpulan}

Untuk mengatasi permasalahan yang dihadapi oleh usaha mikro tempe nasabah lembaga keuangan mikro Kabupaten Sidoarjo sehingga dapat meningkatkan daya saing Usaha Mikro Tempe untuk keberlangsungan usaha di era persaingan MEA darihasil analisis SWOT dan QSPM maka alternatif strategi daya saing Usaha Mikro Tempe yang telah mendapatkan pembiayaan dari LKM, sehingga mampu menciptakan keberlangsungan usaha di era persaingan MEA ditengah maraknya impor kedelai adalah strategi pengembangan produk dengan melakukan pengembangan jenis dan varian produk tempe khususnya perubahan bentuk dan kemasan yang lebih menarik dan hiegenis sehingga dapat memberi nilai tambah produk dan meningkatkan harga jual, yang pada akhirnya akan meningkatkan keuntungan usaha dan dapat mengatasi kelemahan pada beban biaya bunga kredit yang diberikan oleh lembaga keuangan mikro.

\section{Saran}

Untuk meningkatkan daya saing usaha mikro tempenasabah lembaga keuangan mikro di Kabupaten Sidoarjo, maka harus dilakukan strategi pengembangan produk melalui pengembangan jenis dan variannya khususnya pada bentuk dan kemasan yang lebih menarik agar dapat menciptakan nilai tambah dan harga jual.

\section{DAFTAR PUSTAKA}

Bank Indonesia. 2016. Profil Bisnis Usaha Mikro, Kecil dan Menengah (UMKM). Jakarta, Indonesia: Lembaga Pengembangan Perbankan Indonesia. Retrieved from www.bi.go.id/id/ umkm/penelitian/nasional/kajian/.../Pr ofil Bisnis UMKM.pdf

David, F. R. 2006. Manajemen strategis. (I. S. Budi, Ed.) (Kesepuluh). Jakarta: Salemba Empat.

Departemen Pengembangan UMKM. Bank Indonesia. 2016. Pemetaan dan Strategi. Peningkatan Daya Saing UMKM. ww.bi.go.id. Retrieved from www.bi.go.id/id/umkm/penelitian/nasi onal/kajian/Documents/Pemetaan dan Strategi Peningkatan Daya Saing 
UMKM dalam Menghadapi Masyarakat Ekonomi ASEAN \%282015\%29 dan Pasca MEA 2025.pdf

Freddy Rangkuti. 2014. Teknik Membedah Kasus Bisnis Analisis SWOT: Cara Perhitungan Bobot, Rating dan OCAI.

Holle, F. R., \& Dewi, R. M. 2014. Pengembangan Industri Kecil Tahu pada Sentral Industri Tahu dan Tempe Desa Sepande Kecamatan Candi Kabupaten Sidoarjo. Jurnal Pendidikan Ekonomi (JUPE), 2(3), 1-15. Retrieved from https://scholar.google. co.id/scholar?q=PENGEMBANGAN +INDUSTRI+KECIL+TAHU+PADA + SENTRAL+INDUSTRI+TAHU+D AN+TEMPE+DESA+SEPANDE+KE CAMATAN+CANDI+KABUPATEN +SIDOARJO+Fajrur+Rakhman+Holl e+dan+Retno+Mustika+Dewi\&btnG= $\& \mathrm{hl}=\mathrm{id} \&$ as_sdt $=0 \% 2 \mathrm{C} 5$

Lincoln, S. A. 1995. Metodologi Penelitian Untuk Ekonomi dan Bisnis. Yogyakarta: UPP AMPYKPN.

Nicolescu, O. 2009. Main features of SMEs organisation system. Review of International Comparative Management, 10(3), 405-413. Retrieved from http://rmci.ase.ro/ro/no10vol3/ Vol10_No3_Article1.pdf

Nursiah, T., Kusnadi, N., \& Burhanuddin, B. 2015. Perilaku Kewirausahaan pada Usaha Mikro Kecil (UMK) Tempe di Bogor Jawa Barat.Jurnal Agribisnis Indonesia, 3(2), 145-148. Retrieved from http://jesl.journal.ipb.ac.id/index. php/jagbi/article/view/15709
Statistik, B. P. 2016. Profil Kemiskinan Di Indonesia September 2016. Retrieved from https://www.bps.go.id/Brs/view/ id/1378

Sudaryanto, R., \& Wijayanti, R. R. 2013. Strategi Pemberdayaan Umkm Menghadapi Pasar Bebas Asean. Retrieved from http://www.perpustakaan. kemenkeu.go.id/FOLDERJURNAL/2 014_kajian_pkem_Strategi Pemberdayaan UMKM.pdf

Sugiyono. 2009. Metode Penelitian Bisnis (Pendekatan Kuantitatif, Kualitatif, dan $R \& D)$ (16th ed.). Alfabeta.

Suhartini, A. M. A., \& Yuta, R. 2012. Keterkaitan Lembaga Keuangan Mikro (LKM), Usaha Mikro dan Kecil (UMK) serta Kemiskinan di Indonesia Tahun 2012. Jurnal Ekonomi Kuantitatif Terapan, 7(2), 137-144. Retrieved from ojs.unud.ac.id/ index.php/jekt/article/view/16439

Wheelen, T. L., \& Hunger, J. D. 2011. Concepts in strategic management and business policy. Pearson Education India.

Wignaraja, G., Jinjarak, Y. 2015. Why do SMEs not borrow more from banks? Evidence from the People's Republic of China and Southeast Asia. https://doi.org/http://dx.doi.org/10.213 9/ssrn.2548916 